\title{
Discussion of Chinese Loss Alone Group Pension Problem and Its Solution
}

\author{
Yuyan $\mathrm{Hao}^{1} \&$ Yong $\mathrm{Hao}^{1}$ \\ ${ }^{1}$ School of Management, Shanghai University of Engineering Science, Shanghai, China \\ Correspondence: Yuyan Hao, School of Management, Shanghai University of Engineering Science, Long Teng Road \\ No.333, China. Tel: 86-183-1712-9187. E-mail: hyy_0420@126.com
}

This work was supported by Chinese Social Science Fund Project of aging population and pension security service system research (No. 12BRK008).

Received: March 26, 2014 Accepted: April 23, $2014 \quad$ Online Published: June 4, 2014

doi:10.5430/sass.v1n2p44 URL: http://dx.doi.org/10.5430/sass.v1n2p44

\begin{abstract}
In China, loss alone group, refers to the parents who lost their only child. Most of them are more than 50 years old, it is difficult to give birth to and bring up children, also called the loss alone. With the implementation of the one-child policy, the loss alone group has also been increasingly growing across China in the past 40 years, the pension problem has become one of the social problems that can not be ignored. This paper deeply expounds the main problems of the loss alone group pension issue in China and analyzes the causes, thus provides relevant policies and suggestions to solve this problem.
\end{abstract}

Keywords: loss alone group, the only child, pension problem, family endowment

\section{Introduction}

According to a survey of China Zhi Gong Party published, the total number of Chinese one-child population aged 15 to 30 is about 190 million at present, in this age paragraph the mortality rate is four over ten thousand. The number of newly increasing "loss alone family" is about 76000 every year and there are at least 1 million "loss alone family". At least 2 million childless people are facing huge pension, medical, psychological problems and other difficulties. At the same time, according to the sixth census data, demographers Fuxian Yi concluded that, China will have 10 million "loss alone family" in the future, namely, 20 million loss alone group. The pension problem of them has become a serious social problem,such as:not enough emphasis plight, the helpers are limited,compensation amount is low, policy is too broad, society can't give special care to special family, pay little attention to the elderly's psychological, emotional and other demands and so on. Loss alone group pension problem is not only a matter of their own happiness, but also a matter about the country's development and social civilization.

For loss alone group, while Chinese scholars have obtained certain research results, but in terms of loss alone group pension problems, the number of studies is limited, it is difficult to find the answers from the existing achievements. Therefore, it is necessary to have in-depth systematic analysis aiming at loss alone group pension problem, thought provide the relevant policy recommendations to the problem.

\section{The Main Pension Problems for Loss Alone Group}

In China, there are three main kinds of endowment modes: family endowment, nursing home endowment and community endowment, so this article mainly analyzes loss alone group pension problem from the three pension modes.

\subsection{Family Endowment without A Guarantor}

\subsubsection{Family Endowment without Economic and Living Insurance}

In the aspect of economy, loss alone group tend to spent all of their money on the only child, so once the only child 
dead, they lost the opportunity that their child paid back. Meanwhile, with low retirement income or even no retirement pay, loss alone group could only maintain basic living standard, then encountered economic difficulties, pension problems. Although many provinces have began to give economic assistance to loss alone group, such as: Shanghai government give them 250-300 yuan per month; In Chongqing, loss alone group can get 3120 yuan per person per year. But the economic support level is still very low. In addition, in terms of living, the elderly poor physical health is a very common problem. According to the survey, people over 60 generally suffer from all kinds of chronic diseases in China, and loss alone group lost the opportunity to be taken care by their young child, especially when they are in poor physical condition, living care problem is much more outstanding.

\subsubsection{Endowment without Spiritual Sustenance}

For many normal families, children may be busy with work, and spend little time with the elderly, but their family is complete, and occasionally they can also enjoy the family reunion. For Dink families, the elderly have no children, will be very lonely. But compared with those family, loss alone family must have to bear the pain of losing their child. They lost the only hope for the future, the power of living. The huge psychological pain, often make loss alone group hardly wished to live.

\subsection{Difficulties of Endowment in Nursing Home}

\subsubsection{No Guarantor Sign It}

Since there is no child taking care of loss alone group,they need to stay in a nursing home, but before entering in a nursing homes, signed in agreement by the guarantor is necessary and is the common demand of nursing home.And the guarantor is usually children and immediate family members. If they have no immediate family members, the residential street or the workplace need provide the relevant evidences. But in the loss alone group's eyes, the workplace and community institutions are more reluctant to take risks for them. And according to the consulting, most nursing home said it is difficult to receive loss alone group, some even directly refuse, the reason is that the admission procedures and many problems after admission such as sick and so on are difficult to solve.

\subsubsection{The Small Number of Public Nursing Homes}

At present, China's aging population has entered a rapid development period.According to the civil affairs department authoritative information shows, the country's annual aging population will increase 80.00000-90.00000, the elderly population will reach 248 million by 2020 . According to conservative estimates, the number of current shortfall on nursing home beds is 3 million or more, the gap is also great in professional nurses, there are only 20 million nurses in all of the country's pension agency, and nurses with a nursing certificate are only 20 thousand. Nowadays many public nursing home exist the phenomenon that one bed can be hardly found and needed wait in a long line. For example: In Shanghai, after registration need to queue to check in three or four years; in Beijing, beds appointment should be arranged after a decade.

\subsubsection{The High Cost of Private Nursing Homes}

Although the number of private nursing homes is large, but there is existing such a phenomenon: the fee is low under poor conditions but the elderly do not want to stay; the fees is high under good conditions but they can't afford it. For example: According to Qilu Evening News reported, Laiwu government in Shandong province invested 300 million yuan to build a luxury apartments for the elderly, the bed charges ranging from 1000 yuan to 1900 yuan per month, there are only 25 elderly persons for 106 beds, the nursing home lost 7.00000 yuan opened more than two years; Similarly, according to Worker's Daily reported that a large private nursing home in Beijing, a standard room does not include three meals a day, needs more than 5000 yuan a month, the elderly who live in are having relatively high income,so most of them are retired teachers or doctors. For a normal family, under child's financial support, good nursing home can be selected, but the loss alone group are turned away, because the cost is too high.

\subsection{The Imperfect of Community Endowment System}

Community endowment is one kind of endowment modes that relies mainly on family endowment while community agencies subsidiary. In terms of the elderly home-based care services, relies mainly on door-to-door service while senior citizens' care center endowment.

\subsubsection{The Imperfect of Endowment Facilities}

The first mention of Community endowment was in People's Republic of China elderly Protection Act in August 1996. The law discussed and emphasized the requirements of "developing the community services, and gradually adapting to the needs of the elderly living services, cultural and sports activities, such as disease care, rehabilitation facilities and so on". On this basis, scholars analyzed the feasibility of community endowment, and proposed a 
preliminary framework for building community endowment. The principles of community endowment model is classified as "people-oriented, relying on the community, mutual aid and assistance," and from the elderly health condition, community endowment model are divided into the community home-based care and community nursing agency two subsystems, its core is to provide better service for the elderly. Community endowment is consistent with Chinese urban population aging measures, but for practice, it is still a new thing being explored, there are still some problems. Such as, laws are not perfect, staff shortages, lack of funding, inadequate facilities and so on.

\subsubsection{Narrow Coverage of the Service}

Community endowment is at an early stage of development in China, there are some places starting to exploring. In many urban communities, community endowment is not carried out, even if it is carried out, it is very simple, just limited to establish medical center or sports facilities. And some sports facilities are more suitable for young people. Medical centers also provide free medical examination limited to physical examination. Home-based care services is mainly driven by government purchase, the service is limited to a smaller target range that mainly the people without identification papers, a normal residence permit and a source of income. Some older people are encouraged to buy home-based care services and the government give appropriate subsidies. However, the loss alone group and the people without identification papers, a normal residence permit and a source of income, are two different kinds people. There is no official definition of the view that they could be treated equally.

\section{Cause Analysis of Loss Alone Group Pension Problem}

\subsection{Defects of Legal and One-child Policy}

One-child policy has been Implemented since 1973 in China, at the same time, many families has responded to the policy: giving birth to one child. But they could not avoid the risk that their adult child suddenly encountered death. This risk will be transferred to the family, which directly led to the loss alone group pension issues. Although the government has introduced a number of policies and regulations to protect their basic living, but it could not solve the crisis radically. For example, the People's Republic of China Population and Family Planning Law stipulates that: "If their only child has encountered accident, disability or death, and they could not give birth to and adopt another child, the local government should give the necessary help". We can clearly see that this provision defines the event from a macro level, fails to develop a detailed implementation rules to be implemented. At the same time, the newly revised Elderly Protection Act has been formally implemented since July 1, 2013, does not give special attention to the large number of loss alone group. Although some local governments have began to give them social assistance, but few subsidies can not afford their basic living expenses.

\subsection{The Income Level of Loss Alone Group Is Incompatible with The Level of Economic Development}

Meager income is difficult to solve the fundamental problem. Currently, the elderly pension costs are mainly children's alimony, pensions and retirement insurance. Thanks to most of loss alone group got lower wages and no pension, they spent all of their money on fostering their child, some toke care of sick child during their lifetime even debted, in order to rescue them, they had the economic hardship. Although many provinces began to implement the support policies to the one-child family. Loss alone group can get 100-270 yuan one person per month. However, with the high rapid in the level of economic development, prices are rising. The income sources of loss alone group are limited, they could maintain a low level of living based on the income they received, and it is difficult to solve their pension, health care and other issues.

\subsection{Social Lack of Humane Care}

Once the only child was dead, no one can take care of their daily life, the majority of loss alone families are taking care of each other. Family defect has made loss alone group helpless already, at the same time, the society pay little attention to care for them, and tend to treat them with prejudice and discrimination, resulting in that they close their own life. Coupled with their old age, they live with poor mental and physical condition, and their life become worse and worse.

\subsection{Bounds of Traditional Pension Ideas}

Lack of spiritual solace, they are in a desperate situation. "Raising children for old age" is the traditional idea of the Chinese people. After they gave birth to the child, the child is the center of their life, for the previous generation of parents, the happiness of child's life is the only hope, the child is the driving force of life. But the risk factors in a car accident, disease, disaster are uncertainty, so that they fall into a bitter forever, losing purpose and courage to live. Since the vast majority of Chinese parents do not believe in God, the child is entrusted with the continuation of the 
full meaning of their lives. After the death of the child, parents are very easy to fall into self-enclosed, no longer willing to touch social, spirit on the verge of collapse.

\section{Ways to Solve Loss Alone Group Pension Problem}

Analysis of the above reasons, this paper considers the loss alone pension problem should be solved in many ways. Mobilize all social forces and multi-participants. By integrating various resources, Construct a government-led social security system policy; formate a social assistance standard that matches economic development level, improve the conditions of nursing home and home-care services; create the whole social care atmosphere of loss alone group; in the psychological terms, divert and reduce their pain of losing child.

\subsection{Construct A Government-lad Loss Alone Group Social Security Pension System}

\subsubsection{Loss Alone Group Pension Social Security System}

Currently, there are deletions in loss alone group pension social security system. Population and Family Planning Law in 2001 provides that:"once the only child had accident, disability or death, and parents could no longer give birth to and adopt children, local governments should give them the necessary help". But "necessary help" here is a general provision, there is no standard level of assistance and specific sectors responsible for the assistance, at the same time, we can not see how to implement the rules, the law is lack of detailed rules for the operation. Therefore, we must develop further policies and make a clear national responsibility for loss alone group and establish a social security system to share the risk of one-child families. For example, first of all, we can specify the content of the above; secondly, the local government and the one-child family should construct a health Ping An Insurance for the only child, once the only child had accident, disability or death, their parents would be compensated; Thirdly, we can create pension insurance and medical insurance for one-child parents.

\subsubsection{Loss Alone Group Pension Social Security Laws}

To build loss alone group social security pension system, we should further improve the legal system in China. In particular, we should take loss alone group pension problems into consideration and amend Population and Family Planning Law and Marriage Law as soon as possible to lay the legal foundation for aging. For example:Formulate the national minimum aid standards and the responsibilities of government departments at all levels, modify the provisions of nursing home's guarantor, build the community care service facilities and professional nursing personnel or volunteers teams. Thus, provide a legal basis for loss alone group social security pension system.

\subsubsection{Loss Alone Group Pension Funds}

We suggest that the government should response to loss alone group pension problems: to establish a pension fund;to give a one-time subsidy based on the level of the local average wage, including give them assistance payments per month until their death; to establish pension insurance, medical insurance and disability insurance for loss alone group using the funds, focusing on solving the pension and medical difficulties of these families;to establish a special fund for loss alone group living in difficult led by the government and so on. Proposal to deal with loss alone group social charity: to raise and set up a special pension, health fund, especially for those living in difficult.

\subsection{Increase Economic Investment for Loss Alone Group}

\subsubsection{Raise Aid Standard for Loss Alone Group Pension}

For loss alone group pension problems, the government has also taken certain policies. In 2007, the Population and Family Planning Committee, the Ministry of Finance jointly issued a notice, decided to carry out the loss alone family aid system for experimental pilot. According to this notice, after the death of the only child, loss alone group could not give birth to and adopt anther child, meeting the appropriate conditions, they should be given not less than 80 yuan one person per month and 100yuan aid payments until death by the government. For example: In Beijing, the payment of subsidies have began since 2008, amounting to 200 yuan one person per month; In Shanxi, loss alone group over 60 , in rural areas could get 800 yuan per person per month, in urban could get1000 yuan per person per month. The subsidies depending on the circumstances in different provinces are different, up to thousands yuan or low to only hundreds yuan monthly, these subsidies are difficult to meeting their basic living needs. This requires Chinese government to improve the aid level of the basis living unified, the various provinces improve the standard depending on the circumstances, so that improve loss alone groups living conditions.

\subsubsection{Improve the Conditions of the Nursing Home and Community Endowment}

In addition to family endowment, nursing home is the most important way in China, it is necessary to make loss 
alone group enter into a nursing home. We can make such reforms for nursing home, such as: the government as the guarantor to ensure loss alone group can enter into a nursing home; recommend the relevant regulations, give loss alone group the priority to enter into nursing home; establish a separate nursing home just for loss alone group, so that they can hold together for warmth and so on.

For Community endowment, it should be given a positive development. Therefore, Chinese government should give the community endowment policy and financial support. Faced with a range of problems, we should formulate relevant policies to broaden the sources of funds and improve services and facilities, especially medical care facilities and the coverage of community endowment. Establish the professional staff and volunteer teams to lay the foundation of community endowment. So that loss alone group, whether in urban or rural communities, are able to get the chance to pension.

\subsection{Create A Social Love Atmosphere for Loss Alone Group}

\subsubsection{Do Care Advocacy Work for Loss Alone Group}

Currently, loss alone group has not attracted enough attention and care from society. Therefore, the civil affairs departments and national charitable organizations should establish the database of loss alone group as soon as possible to provide the necessary assistance for them. And we should actively use all means, such as Internet and other media, call on all members to concern about loss alone group. Carry out psychological counseling, obligations rounds, hospice, and other diversified services from all aspects for loss alone group.

\subsubsection{Training Social Service Teams}

First, establish the social workers. Social work is a broad participate social force that is led by government, in order to help others and solve others's difficulties. Currently, loss alone group social service teams are very few. To help them get out of psychological haze and spend a cozy old age, the need for psychological assistance, counseling team formation, training of specialized social workers, improve the quality of social worker teams, are very urgent. Second, establish volunteer teams. For loss alone group who frail and can not take care of themselves living, should be actively taken care of by organized youth volunteers. Meanwhile through launching, guiding volunteer activities, mobilize all kinds of people to participate in community services. To encourage the young and the healthy elderly provide services for loss alone group who frail and can not take care of themselves living. So we can set up a special group of volunteers for loss alone group in every city, we can also call for college students approach loss alone group in their spare time to bring them the warmth of home.

\subsection{Strengthen Psychological Counseling of Loss Alone Group}

\subsubsection{Set Up A Special Counseling Agency for Loss Alone Group}

According to Chinese traditions, the parents often regard their children as the most important part of life, and once the children died young, the spiritual pain is unbearable for them. Therefore, the spiritual assistance is much more important than material assistance for loss alone group. This requires that the government should set up a special counseling or social institution, so that they can continue to live healthily, actively and optimistically or even go into work.

\subsubsection{Encourage Loss Alone Group to Overcome the Idea "Raising Children is for Old Age"}

Currently, family endowment is the main pension model of Chinese pension models. Once they lost the only child, the parents just like fell from a cliff into the abyss. Faced with loss alone group pension problem, we must not only be based on Chinese national pension system, but also need to learn from other countries. Such as: encourage loss alone group actively participate in social activities. In addition, Chinese religions are permitted, and there are a considerable number of people believing in religion, so encourage loss alone group believe in religion, which can improve the quality of their spiritual life and reduce loneliness.

\section{Conclusion}

First, analysis the main pension problems and the reasons loss alone group are facing: there are no economic, living and spiritual security in family endowment, entering in nursing home is difficult, home-care system is not perfect; reasons are that defects of legal and one-child policy, low income levels, social lack of humane care, bounds of traditional pension ideas.

Second, find solutions to loss alone group pension problems: construct a government-lad loss alone group social security pension system, increase economic investment, create a social love atmosphere, strengthen psychological 
counseling.

\section{References}

Che, Hui. (2010). Nursing Homes: Private is Too Expensive, Public is Too Few. Evening workers News.

Chen, Lina, \& Zhao, Guiying. (2011). Foreign Experience to Build Chinese Pension Model. Hengshui College News.

Cheng, Lingrun. (2013). Private Nursing Home Losses 7,00 000 Yuan Two Years. Qilu Evening News.

Dong, Lihong. (2012). The Thinking of Loss Alone Family Pension Problem. Suihua College News.

Dong, Wanyu. (2013). Listening Loss Alone Family Complained Dilemma. Yangzi Evening News.

Hu, Diequan, \& Xing, Qishun. (2013). Construction of Loss Alone Group Pension Security System. Gorges forum.

Li, Hongxi, \& Li, Wei. (2012). Researches on Pension Modes. Economics and Management.

Song, Qiangling. (2013). Loss Alone Family Pension Problems and Countermeasures. Community Livelihood.

Xu, Yun. (2013). The Analysis of Reality Difficulties and Countermeasures for Loss Alone Group Ideological and Political Education. Suzhou Education Institute. 